\title{
Written Emotional Expression and Emotional Well-Being: The Moderating Role of Fear of Rejection
}

\author{
Thomas A. Langens \\ University of Wuppertal, Germany \\ Julia Schüler \\ University of Zürich, Switzerland
}

Empirical research shows that individuals high in fear of rejection typically report low levels of perceived social support and are more vulnerable to stressful experiences. At the same time, writing about stressful experiences in an emotional way seems to help people adapt to current stressors and not-yet-assimilated stressful experiences. Therefore, the authors suggest that written emotional expression may be a particularly effective strategy to manage negative emotions for individuals high in fear of rejection. Three studies were conducted to test these assumptions. Study 1 found that high fear of rejection is linked to a lack of perceived social support. Longitudinal Studies 2 and 3 supported our main hypothesis, demonstrating that written emotional expression is linked to lower levels of negative mood among individuals high (but not among individuals low) in fear of rejection.

Keywords: written emotional expression; fear of rejection; emotional well-being; coping

M ost people cannot avoid the stresses of daily life, such as arguments with friends or family, time pressure, or being bossed around at work. A significant number of individuals are confronted with more serious events such as losing their job, a car crash, the end of a romantic relationship, or a serious illness. When confronted with stressful events, many people find comfort in the belief that friends and family care and are willing to provide help and assistance if necessary. In the following, we will first review research that suggests that individuals high in fear of rejection may be cut off from the stress-buffering effects of perceived social support. We will then discuss written emotional expression as an intentional strategy that helps people deal with current or not-yet-assimilated stressful events. Integrating these two bodies of

research, we will suggest that written emotional expression may be especially beneficial for individuals high in fear of rejection.

\section{SOCIAL SUPPORT, FEAR OF REJECTION, AND COPING WITH STRESS}

An important variable that influences an individual's capacity to deal with stressful events seems to be perceived social support. A large body of evidence has demonstrated that perceptions of social support predict speedier and better adjustment to stressful events (e.g., S. Cohen, 1992; Coyne \& Downey, 1991; Stroebe \& Stroebe, 1996). Interestingly enough, the association between social support and adjustment to stress is most probably not mediated by received social support: Actually receiving social support does not seem to improve adjustment to stressful life experiences (Bolger, Foster, Vinokur, \& Ng, 1996; Eckenrode \& Wethington, 1990), especially if the benefactor is aware of receiving support (Bolger, Zuckerman, \& Kessler, 2000). These findings suggest a direct link between perceptions of social support and the capacity to deal efficiently with stressful events: The simple belief that other people care, that one is valued, or likely to receive help when it is needed often seems to be sufficient for stress-buffering effects to occur.

Authors' Note: We wish to thank Dorothea Krämer for her help in data collection. Correspondence concerning this article should be addressed to Thomas A. Langens, Department of Psychology, University of Wuppertal, Gaussstrasse 20, 42097 Wuppertal, Germany; e-mail: langens@uni-wuppertal.de

PSPB, Vol. 31 No. 6, June 2005 818-830

DOI: $10.1177 / 0146167204271556$

(C) 2005 by the Society for Personality and Social Psychology, Inc. 
On the other hand, this body of research suggests that people who do not feel liked or supported by peers, family, or friends may be less able to cope efficiently with stressful events. One variable that is linked to low perceptions of social support is fear of rejection. Individuals with a strong (relative to weak) fear of rejection feel more insecure in social situations and typically transmit feelings of insecurity to the people around them; they feel more uncomfortable and anxious in social groups, believe they are less liked by peers and friends, and frequently anticipate being rejected by other people (Mehrabian \& Ksionzky, 1974; Sokolowski \& Schmalt, 1996; Vorauer, Cameron, Holmes, \& Pearce, 2003). Because individuals high in fear of rejection tend to doubt that they are liked and valued, they may be cut off from the buffering effects that perceived social support can offer.

There are some empirical data supporting this conclusion. Connor-Smith and Compas (2002) found that individuals high (relative to low) in sociotropy (i.e., individuals who place extreme importance on maintaining relationships and avoiding rejection) report being confronted with a higher number of social stressors. Sokolowski and Schmalt (1996) found that among participants who imagined entering a social situation, those high in fear of rejection reported being more anxious and uptight and showed higher physiological arousal. An experiment by Pierce and Lydon (1998) suggests that fear of rejection may undermine an individual's capacity to cope efficiently with a stressful situation. In this study, Pierce and Lydon (1998) primed either positive interpersonal expectancies (by subliminally presenting words such as caring, accepting, and loving) or negative interpersonal expectancies (by using words such as rejecting, critical, and distant) before having their female participants imagine an unplanned pregnancy. Compared to a control group in which no priming occurred, priming negative interpersonal expectancies was related to a less positive mood and to less growth-oriented coping (i.e., participants were less likely to agree to items such as "I found new faith" or "I changed or grew as a person") immediately after imagining an unplanned pregnancy.

Because individuals high in fear of rejection typically expect other people to be rejecting, critical, or distant (cf. Mehrabian \& Ksionzky, 1974), they seem to be less able to automatically adapt to stressful experiences. In the following, we argue that written emotional expression may be a strategy that may compensate for the lack of perceived social support experienced by individuals high in fear of rejection.

\section{Coping Through Written Emotional Expression}

There is now solid evidence that writing about important personal experiences in an emotional way can improve physical health and subjective emotional wellbeing. In their seminal study, Pennebaker and Beall (1986) had participants write about the most traumatic experience of their life for 15 minutes a day over the course of 4 days and found that students who elaborated traumatic experiences both cognitively and emotionally subsequently reduced the number of health center visits. A meta-analysis of writing studies conducted subsequently (Smyth, 1998) demonstrated that written emotional expression not only improves reports of physical health but also has beneficial effects on blood markers of immune functions, general functioning, and subjective emotional well-being. Although writing about traumatic or stressful experiences may increase negative mood immediately afterwards, participants who wrote about traumatic experiences (relative to trivial topics) typically report improved emotional well-being if questioned at least 2 weeks after the writing intervention (Francis \& Pennebaker, 1992; Park \& Blumberg, 2002).

Discussions of the mechanisms that may be responsible for the effects of emotional expression (e.g., Pennebaker \& Seagal, 1999; Smyth, 1998) typically highlight the importance of forming a narrative and developing a new meaning of stressful events. According to Pennebaker and Seagal (1999), writing about stressful events can help to integrate stressful experiences into a coherent narrative that may render the traumatic experience more meaningful. Once a person has developed a new meaning of the stressful experience, the event can "be summarized, stored, and forgotten more efficiently" (Pennebaker \& Seagal, 1999, p. 1248). In support of this assumption, Pennebaker, Mayne, and Francis (1997; see also Klein \& Boals, 2001) found that participants who increased the usage of insight words during the course of the writing period showed the largest decreases in number of health center visits. Neither participants who used many insight words at the beginning of the intervention (i.e., who had a fixed conception of the stressful event) nor participants who did not use many insight words at all (who did not find any meaning in the event) benefited as much from the writing intervention. These studies suggest that developing a new meaning of stressful events is indeed vital for positive effects of emotional expression to occur.

\section{The Present Research}

Emotional expression, either written or verbal, is a common intentional strategy to cope with stressful events. In many cultures, people who face stressful experiences or suffer from negative emotional states turn to friends, priests, psychotherapists, or their diary and talk or write about their experience in an effort to reduce current negative emotions (see, e.g., Georges, 1995; Parkinson \& Totterdell, 1999; Rosenblatt, Meyer, \& Karis, 1991-1992; 
Wellenkamp, 1995). Because emotional expression can be employed deliberately, we suggest that it may be successfully adopted by individuals high in fear of rejection to compensate for their higher vulnerability to stressful events induced by low perceptions of social support. We do not suggest that emotional expression necessarily changes perceptions of social support in individuals high in fear of rejection. Instead, emotional expression may work for individuals high in fear of rejection as some sort of fail-safe device that can be resorted to if the stressbuffering effects of perceived social support are not available. Facing stressful events, individuals low in fear of rejection are reassured by the feeling that they can rely on the support of family and friends, which may help them to cope efficiently with adversity. Lacking the reassurance provided by perceived social support, individuals high in fear of rejection may benefit from employing emotional expression as an alternative way to cope with stress. Following Pennebaker and Seagal (1999), we assume that emotional expression is beneficial for individuals high in fear of rejection because it provides them with a new understanding of stressful experiences.

We conducted three studies to explore (a) the relationship between fear of rejection and perceived social support and (b) the role of fear of rejection in moderating the effects of written emotional expression on subjective emotional well-being. Study 1 tested whether individuals high in fear of rejection indeed perceive less social support in close relationships. Studies 2 and 3 tested whether the effects of emotional expression depend on an individual's fear of rejection. In Study 2, the experimental group wrote about a past stressful experience, whereas in Study 3, participants wrote about self-defining memories. Subjective emotional well-being was assessed in both studies before the writing intervention and again either 6 weeks (Study 2) or 5 weeks (Study 3 ) after the writing period. Studies 2 and 3 aimed at predicting changes in negative mood, as stressful and traumatic experiences primarily arouse negative mood while having less impact on positive mood (e.g., Suh, Diener, \& Fujita, 1996). Fear of rejection was assessed using the Multi-Motive Grid (MMG) (Sokolowski, Schmalt, Langens, \& Puca, 2000), a comprehensive measure of motivation that has been demonstrated to yield valid indicators of motivation in a number of studies (e.g., Gable, Reis, \& Elliot, 2003; Kehr, 2004).

We also addressed two further issues in our research. One important methodological issue concerns the role of neuroticism as a potential nuisance variable in empirical research on mood and mood changes. Individuals high in neuroticism generally report higher levels of negative affect, and most researchers recommend measuring and statistically controlling neuroticism in studies on physical symptoms and emotional well-being (Costa
\& McCrae, 1987; Elliot \& Sheldon, 1998; Emmons \& King, 1988). Hence, we assessed neuroticism and controlled for its effect on mood changes during the course of Studies 2 and 3. A second issue concerns the specificity of fear of rejection as a possible moderator of the effects of written emotional expression. We specifically predict fear of rejection to moderate the consequences of written emotional expression, because fear of rejection is linked to low perceived social support. If this argument holds, then other personality dispositions that are also associated with high negative affectivity, but are unrelated to perceived social support, should have no moderating effect on the consequences of emotional writing. The two dispositions tested as alternative moderators in Studies 2 and 3 were neuroticism and fear of failure. Whereas both variables are associated with increased negative affectivity (e.g., Costa \& McCrae, 1987; Langens \& Schmalt, 2002), there is no conclusive evidence that either neuroticism or fear of failure is linked to low perceived social support.

STUDY 1: FEAR OF REJECTION AND

LACK OF PERCEIVED SOCIAL SUPPORT

A lack of perceived social support has frequently been assessed in terms of stressors encountered in close relationships (e.g., Holahan, Moos, Holahan, \& Brennan, 1997; Vinokur \& Van Ryan, 1993). In fact, Coyne and Downey (1991) stated that "perceived support may often best be viewed as the absence of particular kinds of adversity in interpersonal relationships" (p. 420). In Study 1, participants rated how much they had experienced a number of stressors in the previous week. The list of daily hassles employed in this study included events related to interpersonal experiences as well as hassles related to changes in living conditions and assorted annoyances. We expected fear of rejection (but not fear of failure) to be related to an increased perception of interpersonal hassles.

\section{Method}

\section{PARTICIPANTS AND PROCEDURE}

Participants were 109 students (54 women and 55 men) of the University of Wuppertal, who received course credit for participation. Participants (mean age $=$ 24.4 years, $S D=5.03$ ) completed the MMG to assess fear of rejection and fear of failure and a questionnaire assessing daily hassles.

\section{MOTIVE ASSESSMENT}

The MMG (Sokolowski et al., 2000) was administered to assess the hope and fear components of the achievement (hope for success and fear of failure) and affiliation (hope for affiliation and fear of rejection) motives. It consists of 14 pictures that depict a variety of everyday 
situations that are presented along with a set of statements describing typical thoughts, feelings, and action tendencies. Internal consistency and retest reliability for the different motive measures are sufficiently high (see Sokolowski et al., 2000, for details). The index of fear of rejection represents the inclination to have thoughts about being boring to other people or about possible rejection. Statements assessing fear of failure describe the inclination to have thoughts related to avoidance and the lack of abilities in achievement situations. The validity of the MMG has been demonstrated repeatedly (e.g., Gable et al., 2003; Kehr, 2004; Langens \& Schmalt, 2002; Sokolowski et al., 2000). Fear of rejection $(\alpha=.79)$ and fear of failure $(\alpha=.75)$ had sufficient internal consistency.

\section{DAILY HASSLES}

Daily hassles were assessed using the Short Inventory of Stress for Students (SISS), a measure of different sources of stress typically experienced by university students (see Langens \& Stucke, in press). The SISS consists of 13 items that ask for assorted annoyances (three items), changes in living conditions (four items), study stress (three items), and interpersonal stress (three items). Descriptions of hassles were introduced by the sentence stem "In the last week, I have experienced...." Interpersonal hassles were assessed by the items " . . . strains in the family life," "... problems with girlfriend/ boyfriend or spouse," and "... arguments or fights with friends." Items had to be rated on a 5-point scale with endpoints labeled not at all (1) and extremely (5). In the present sample, the SISS scales showed low to moderate internal consistency ( $\alpha$ 's ranging from .33 to .54). Low internal consistencies should be expected when aggregating items because one source of hassles (e.g., strains in the family life) is not necessarily associated with hassles in a different domain (e.g., problems with a spouse or a friend). Hence, summary scores do not reflect scales that meet the criteria of classical test theory but rather indexes (cf. Streiner, 2003) of stress related to different life domains.

\section{Results and Brief Discussion}

As can be seen in Table 1, fear of rejection significantly correlated with interpersonal hassles but was unrelated to study stress, change in living conditions, and assorted annoyances. Analyses for single items of the SISS showed that fear of rejection was significantly related to "problems with girlfriend/boyfriend or spouse" $(r=.29, p<.01)$ but unrelated to "strains in the family life" $(r=.08, p>.40)$ and "arguments or fights with friends" ( $r=.14, p>.15)$. However, because the relationship between fear of rejection and the aggregate score of interpersonal stress $(r=.35, p<.001)$ was stronger than
TABLE 1: Correlations Between Fear Motives and Hassles (Study 1, $n=109$ )

\begin{tabular}{lcccc}
\hline & $\begin{array}{c}\text { Interpersonal } \\
\text { Hassles }\end{array}$ & $\begin{array}{c}\text { Study } \\
\text { Stress }\end{array}$ & Change & $\begin{array}{c}\text { Assorted } \\
\text { Annoyances }\end{array}$ \\
\hline Fear of rejection & $.35^{\S}$ & -.06 & -.02 & .04 \\
Fear of failure & -.08 & -.10 & $.20^{* * * *}$ & -.01 \\
\hline
\end{tabular}

$* * * p<.05 .{ }^{\S} p<.001$.

the correlations with single items, it seems safe to conclude that fear of rejection is generally related to increased perceptions of stress in interpersonal relationships. As expected, fear of failure was not related to interpersonal hassles.

Because interpersonal stressors are central markers of a lack of perceived social support (cf. Coyne \& Downey, 1991), we can conclude that individuals high in fear of rejection are at risk for low perceptions of social support. Specifically, a high fear of rejection predisposes an individual to experience stressors in close relationships, which are typically seen as the most important source of perceived social support (Stroebe \& Stroebe, 1996). As a consequence, individuals high in fear of rejection may not benefit from the stress-buffering effects that social support offers. In Studies 2 and 3, we tested whether emotional expression can compensate for a lack of perceived social support in individuals high in fear of rejection.

\section{STUDY 2: WRITING ABOUT STRESSFUL EXPERIENCES}

In Study 2, participants in the experimental condition wrote about one or more past stressful experiences. The instructions were largely adopted from Pennebaker's writing studies (e.g., Pennebaker \& Beall, 1986), except that participants were not specifically instructed to write about the most traumatic experience of their life. Participants in the control condition were asked to write about trivial topics. Negative mood was assessed before the writing intervention and again 6 weeks after participants finished writing. Study 2 also tested whether developing a new meaning of stressful experiences is crucial for the beneficial effects of written emotional expression to occur.

\section{Method}

\section{PARTICIPANTS AND OVERVIEW OF PROCEDURE}

Data were collected in three phases. At the beginning of the semester (Time 1, or T1), 88 students (63 women and 25 men) were recruited for a study on "writing and psychology" and received a take-home booklet that contained questionnaires assessing motives, neuroticism, and negative mood. After participants had returned the 
booklet, they were assigned randomly to one of two conditions (T2): an experimental group asked to write about stressful events $(n=44)$ or a control group asked to write about trivial topics $(n=44)$. Students were allowed to write their essays at home but were reminded to start writing essays the same night. In both conditions, participants were informed that they were free to drop out of the study at any time. Although 16 participants of the experimental condition (36\%) decided to discontinue their participation, only 3 participants in the control condition $(9 \%)$ elected to drop out of the study, $\chi^{2}(1, n=88)=11.34, p<.001$. Six weeks after participants finished writing their essays (T3), they were again asked to fill out a mood measure. Four participants ( 2 in each condition) failed to pick up the follow-up questionnaire or could not be contacted. Thus, complete data sets were obtained for 65 participants (experimental condition: $n=26$; control condition: $n=39$ ).

\section{MEASURES}

Motives. As in Study 1, motives were assessed using the MMG.

Neuroticism. Neuroticism was assessed at T1 using the scale from the Five-Factor Inventory (Neo-FFI, German translation by Borkenau \& Ostendorf, 1993). Participants rated 12 items on a 6-point scale with endpoints labeled strongly disagree (1) and strongly agree (6). After reversing negatively keyed items, internal consistency was high $(\alpha=.91)$. Thus, we computed scores for neuroticism by averaging responses over the 12 items $(M=3.11, S D=0.71)$.

Mood assessment. Participants' mood was assessed at T1 and T3 using Shacham's (1983) shortened version of the Profile of Mood States (POMS) (McNair, Lorr, \& Droppleman, 1971). Because we were mainly interested in negative mood, participants filled out items assessing tension-anxiety (e.g., tense, nervous, anxious), depression-dejection (e.g., discouraged, hopeless, worthless), and fatigue-inertia (e.g., worn out, fatigued, exhausted). Participants were asked to read each adjective and to indicate on a 5-point scale with endpoints labeled not at all (1) and extremely (5) "how much you have had that particular feeling during the past week." Mood scores were derived by averaging ratings for each scale. The resulting scales were combined to give a single comprehensive measure of negative $\operatorname{mood}(\mathrm{T} 1: M=$ 2.51, $S D=0.69, \alpha=.90 ; \mathrm{T} 3: M=2.52, S D=0.76, \alpha=.90)$.

\section{WRITING INTERVENTION}

In the experimental condition, participants were asked to write about upsetting emotional experiences on 4 consecutive days for 20 minutes each day. They were assured that their essays would be anonymous and that they would not receive feedback on them. Following Pennebaker's (Pennebaker \& Beall, 1986) instructions, participants were told,

I would like you to pick one or more events which were very upsetting and which aroused strong negative emotions. You may want to write about events you haven't talked about with anybody before. In your writing, I'd like you to really let go and explore your deepest emotions and thoughts. You might tie your topic to your relationships with others, including parents, lovers, friends, or relatives, to your past, your present, or your future, or to who you have been, you would like to be, or who you are now.

Participants in the control condition were asked to write about an assigned topic on each of 4 days and to spend 20 minutes on each essay. Following Pennebaker and Beall (1986), the topics included trivial issues such as "My way to school" and "My apartment." The experimenter emphasized that participants should refrain from discussing emotions or feelings in their essays.

Participants were asked to rate whether they had developed a new meaning of the topic of their essays twice, a first time directly after having written about either emotional experiences or assigned topics and again at T3. The two items ("After having written about the experience, I understand things more clearly than before" and "Writing about the experience did not increase my understanding of the experience," reversed) had to be rated on a 7-point scale with endpoints labeled strongly disagree (1) and strongly agree (7). After reversing the negatively keyed item, internal consistency was sufficient for both T2 $(\alpha=.75)$ and T3 $(\alpha=$ $.77)$. Meaning scores were derived by averaging ratings for the two items (T2: $M=2.81, S D=0.99$; T3: $M=2.77$, $S D=0.96)$.

Results

\section{PARTICIPANT ATTRITION AND PRELIMINARY ANALYSES}

Participants in the experimental condition who decided to drop out of the study after filling out the initial questionnaires did not differ from participants completing the study in terms of fear of rejection, $t(42)=.02$, $p>.90$; fear of failure, $t(42)=.92, p>.35$; and negative $\operatorname{mood}$ at $\mathrm{T} 1, t(42)=.12, p>.90$. However, students who quit their participation tended to score lower on hope for success than participants completing the study $\left(M_{\text {dropped out }}=4.88, S D=2.25\right.$ vs. $\left.M_{\text {completed }}=6.07, S D=2.34\right)$ $t(42)=1.69, p<.10$. Asked why they chose to quit their participation, most students responded that they "didn't feel like" writing about upsetting events. Thus, the generalizability of the results may be slightly restricted by 
TABLE 2: Descriptive Statistics and Two-Tailed Correlations Among Variables (Study 2, $n=65$ )

\begin{tabular}{lccccccc}
\hline & 1 & 2 & 3 & 4 & 5 & M & \\
\hline 1 Fear of rejection & $(.76)$ & $.37 * * * *$ & $.39 * * * *$ & $.28^{* * *}$ & $.26^{* * * *}$ & 5.61 \\
2 Fear of failure & & $(.75)$ & $.42^{* * * *}$ & $.29^{* * *}$ & .19 & 2.61 \\
3 Neuroticism & & $(.91)$ & $.44^{* * * *}$ & $.44^{* * * *}$ & 3.11 & 2.41 \\
4 Negative mood, Time 1 & & & $(.90)$ & $.51^{* * * *}$ & 2.49 \\
5 Negative mood, Time 3 & & & & $(.90)$ & 0.71 & 2.51 \\
\hline
\end{tabular}

NOTE: Figures in parentheses are reliabilities estimated by coefficient alpha.

$* * * p<.05$. ***** $p<.01$.

TABLE 3: Hierarchical Regression of Negative Mood at Time 3 (Study 2)

\begin{tabular}{|c|c|c|c|c|c|}
\hline Step & Variable & $\Delta \mathrm{R}^{2}$ & df & $\Delta \mathrm{F}$ & $\beta^{\mathrm{a}}$ \\
\hline \multirow[t]{3}{*}{1} & Control variables & .313 & 2,62 & $14.11 * * * *$ & \\
\hline & Negative mood at Time 1 & & & & $.39 * * * *$ \\
\hline & Neuroticism & & & & $.27 * * *$ \\
\hline \multirow[t]{3}{*}{2} & Main effects & .006 & 2,60 & .26 & \\
\hline & Fear of rejection (FR) & & & & .06 \\
\hline & Experimental condition & & & & -.05 \\
\hline 3 & FR $\times$ Experimental Condition & .073 & 1,59 & $7.04 * * *$ & $-.37 * * *$ \\
\hline \multicolumn{2}{|c|}{ Cumulative $R^{2}$} & .397 & 5,55 & $7.25 * * *$ & \\
\hline
\end{tabular}

a. $\beta$ is the standardized regression coefficient in the regression equation.

$* * * p<.05$. ***** $p<.01$.

participant attrition. Further preliminary analyses revealed that neither age nor gender of the participants had a significant impact on the results reported below.

\section{DESCRIPTIVE STATISTICS AND \\ INTERCORRELATIONS OF VARIABLES}

Table 2 shows that fear of rejection, fear of failure, and neuroticism were significantly correlated. As might be expected, fear of rejection was positively related to neuroticism and negative mood at $\mathrm{T} 1$.

\section{NEGATIVE MOOD AT T3}

Participants' negative mood at T3 was analyzed by employing the following hierarchical regression approach $^{1}$ (see Table 3). After controlling for negative mood at $\mathrm{T} 1$ and neuroticism (Step 1), we entered fear of rejection and the experimental condition (dummy coded) into the regression equation (Step 2), followed by the multiplicative interaction of fear of rejection and the experimental condition (Step 3). After controlling for initial negative mood and neuroticism, the interaction of the experimental condition and fear of rejection predicted negative $\operatorname{mood}$ at T3, $\beta=-.40, S E_{\mathrm{b}}=.16, \Delta R^{2}=$ $.073, t(59)=2.54, p<.05$. To explore the nature of this interaction, we calculated predicted values of negative mood at T3 using the regression weights from the final regression equation by employing a procedure proposed by P. Cohen, Cohen, West, and Aiken (2003), in which values at 1 standard deviation above or below the mean of continuous predictor variables are entered in the regression equation. The result of this procedure is illustrated in Figure 1, which suggests that individuals high in fear of rejection reported lower levels of negative mood at the end of the semester when they wrote about stressful (vs. trivial) events. Supplementary post hoc analysis that employed a variant of the Johnson-Neyman technique (see Aiken \& West, 1991, p. 132) revealed that the difference between the two writing conditions was not significant for individuals low in (1 standard deviation below the mean of) fear of rejection, $t(59)=1.54, p=$ .13 , two-tailed test, but significant for individuals high in (1 standard deviation above the mean of) fear of rejection, $t(59)=2.25, p<.05$, two-tailed test. ${ }^{2}$

Next, we tested whether neuroticism or fear of failure also moderated the effects of the writing intervention on negative mood at T3. In a hierarchical regression similar to the regression reported above, negative mood at T3 was analyzed by employing the following regression approach: Initial negative mood and neuroticism were entered in Step 1, followed by the writing condition and fear of failure in Step 2, and the interaction of predictors in Step 3. In a second hierarchical regression analysis to predict negative mood at T3, initial negative mood was entered in Step 1, followed by neuroticism and the experimental condition in Step 2, and their multiplica- 


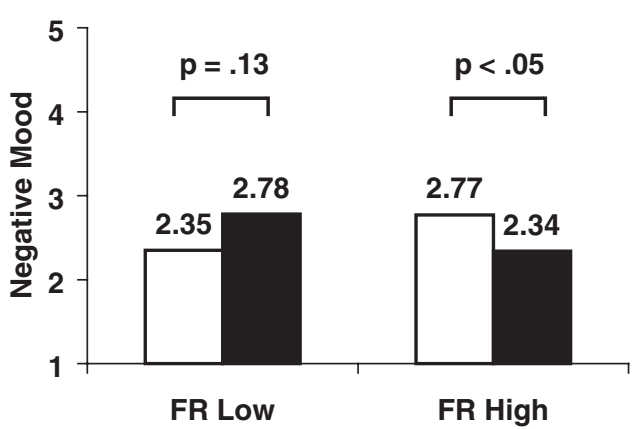

Trivial Topics $\square$ Stressful Experiences

Figure 1 Negative mood at Time 3 as a function of the writing intervention and fear of rejection (Study 2).

NOTE: $F R=$ fear of rejection.

tive interaction in Step 3. In these analyses, the interaction term did not reach significance for fear of failure, $\beta=-.01, S E_{\mathrm{b}}=.17, t(59)=.55, p>.50$; nor for neuroticism, $\beta=-.06, S E_{\beta}=.23, t(60)=.15, p>.80$. Thus, fear of rejection uniquely predicted the differential effects of the writing condition on negative mood.

\section{SUPPLEMENTAL ANALYSES}

To test whether meaning attributed to the topic of the writing intervention was associated with fear of rejection and changes in negative mood, a series of additional analyses was run. First, a 2 (Condition: writing about emotional events vs. trivial topics) $\times 2$ (Time: meaning at T2 and T3) mixed factorial ANOVA yielded a statistical trend for condition, $F(1,63)=2.85, p<.10$. On average, participants rated the writing intervention as more meaningful in the experimental condition (T2: $M=$ $3.04, S D=1.08$; T3: $M=2.98, S D=1.00)$ than in the control condition (T2: $M=2.65, S D=0.91$; T3: $M=2.62, S D=$ $0.91)$. Neither the effect of time nor the interaction of factors reached significance. Next, a hierarchical regression of meaning (T3) on fear of rejection and the experimental condition (controlling for meaning at T2) yielded a significant interaction of fear of rejection and the experimental condition, $\beta=.46, S E_{\beta}=.19, \Delta R^{2}=.055$, $t(60)=2.43, p<.05$. Participants high in fear of rejection who wrote about emotional experiences rated the intervention as more meaningful at $\mathrm{T} 3$ (predicted value $=$ 3.15) than participants low in fear of failure writing about emotional topics (predicted value $=2.51$ ). For participants writing about trivial topics, meaning scores were low for both individuals high in fear of rejection (predicted value $=2.57$ ) and for those low in fear of rejection (predicted value $=2.85$ ).

To investigate the associations between changes in meaning and negative mood, scores for meaning and negative mood were residualized by regression (thus controlling for initial levels) and correlated with fear of rejection. In the experimental condition, fear of rejection was significantly associated with an increase in meaning $(r=.47, p<.05)$, and an increase in meaning was associated with a reduction in negative mood $(r=$ $-.43, p<.05)$. The zero-order correlation between fear of rejection and a reduction in negative $\operatorname{mood}(r=-.31, p=$ .11) was reduced after controlling for change in meaning $(p r=-.14, p>.50)$. Sobel's test indicated a statistical trend for the indirect path being significantly different from zero, $t(24)=1.73, p=.08$. In the control condition, fear of rejection was not related to changes in meaning $(r=-.16, p>.30)$, and changes in meaning were not associated with changes in negative $\operatorname{mood}(r=.10, p>.50)$.

\section{Brief Discussion}

The results of Study 2 support our hypothesis that fear of rejection moderates the effects of written emotional expression. Participants high in fear of rejection reported a significantly less negative mood 6 weeks after writing about stressful experiences than individuals high in fear of rejection writing about trivial topics. Among individuals low in fear of failure there were no significant differences between participants who had written about stressful experiences and those who had written about trivial topics. The moderating effect of fear of rejection was obtained after statistically controlling for neuroticism, a potential nuisance variable in research on emotional and physical well-being. Additional analyses showed that other variables that were also assessed in Study 2-neuroticism and fear of failure-did not moderate the consequences of emotional writing.

Supplemental analyses found some evidence that individuals high in fear of rejection benefited from emotional expression because the writing intervention had furnished them with a new meaning of the events which they had described in their essays. Among participants writing about emotional experiences, individuals high (relative to low) in fear of rejection reported having developed a deeper understanding through emotional expression, and an increase in meaning was related to a decrease in negative mood. In the control condition, changes in meaning were unrelated to both fear of rejection and changes in negative mood. Although our empirical evidence rests on a small sample, it is fully in accord with Pennebaker's (Pennebaker \& Seagal, 1999) assumption that developing a new understanding of stressful events is necessary for the beneficial effects of emotional expression to occur.

A problem with Study 2 was the high attrition rate in the experimental condition. After having learned that they had to write about highly stressful experiences, roughly one third of the participants decided to quit their participation in the study. This is much higher than 
the attrition rate typically reported in writing studies. We suspect that by allowing participants to write at home, and thus giving them time to contemplate their decision, some participants may have anticipated the immediate consequences of emotional expression (e.g., increases in negative mood, see Smyth, 1998) and may then have decided to quit their participation. These results clearly show that some people may find it hard to articulate highly stressful events and given a choice, may refrain from doing so. Thus, we modified the writing intervention in Study 3 in an attempt to motivate as many participants as possible to complete the study.

\section{STUDY 3: WRITING ABOUT SELF-DEFINING MEMORIES}

In Study 3, participants in the experimental condition wrote about self-defining memories (Singer \& Moffitt, 1991-1992; Singer \& Salovey, 1993). According to Singer and Salovey (1993), self-defining memories are vivid, repetitive memories that focus on enduring concerns or unresolved conflicts, are highly charged emotionally, and help to explain to an individual how she came to be the person she is. Self-defining memories seemed appropriate for the writing intervention because of their emotional quality and because they deal with enduring concerns and unresolved conflicts. By having participants write about self-defining memories, we hoped to secure the beneficial effects of written emotional expression while at the same time motivating most participants to continue their participation in the study.

In his meta-analysis, Smyth (1998) found that writing interventions were more effective if they were spaced out over a longer time period. Therefore, we had participants write about self-defining memories over a period of 8 weeks in Study 3, hoping that such a comparatively long period might compensate for the lesser emotional intensity of self-defining memories as compared to stressful or traumatic experiences. Thus, after an initial baseline assessment of mood, participants wrote about self-defining memories for 8 weeks. Five weeks later, mood was measured again.

For two reasons, we decided to include a nonwriting control condition in Study 3 rather than having control participants write about trivial topics. First, we thought that asking participants to write about trivial events for 8 consecutive weeks might induce a sense of anger or frustration that could artificially induce a negative mood or discontent with the study. Second, two studies that included both a writing control condition and a nonwriting control condition (Richards, Beal, Seagal, \& Pennebaker, 2000; Spera, Buhrfeind, \& Pennebaker, 1994) did not find significant differences between the two control conditions. Thus, we expected the nonwriting control condition to be a valid comparison group for the writing intervention realized in Study 3.
As in Study 2, neuroticism and fear of failure were assessed and tested as moderators of the effects of written emotional expression.

Method

\section{PARTICIPANTS AND OVERVIEW OF PROCEDURE}

Seventy-one first-year university students (56 women, 13 men, and 2 participants who did not disclose their gender) were recruited for a study on "writing and psychology." Data were collected in three phases. At the beginning of the semester (T1), participants received a take-home booklet that contained questionnaires assessing motives, neuroticism, and $\operatorname{mood}^{3}$. Upon returning the booklet, participants were assigned randomly to one of two conditions (T2). The experimental group was asked to write about self-defining memories $(n=36)$; another group of participants served as a nonwriting control group $(n=35)$. At the end of the semester (T3, 13 weeks after the recruitment), participants were asked to fill out the mood measure a second time. The data of 1 participant was discarded because he failed to complete all the questionnaires. The mean age of participants was 25.29 years $(S D=7.36)$.

\section{MEASURES}

Motives. As in Studies 1 and 2, motives were assessed using the MMG.

Neuroticism was assessed by administering the same questionnaire employed in Study 2. After reversing negatively keyed items, responses were averaged to give a single score for neuroticism $(M=2.79, S D=.66, \alpha=.78)$.

Mood. As in Study 2, negative mood was assessed at T1 and T3 using the POMS-Revised (Shacham, 1983). As in Study 2, we combined the scales Tension-Anxiety, Depression-Dejection, and Fatigue-Inertia to give a single comprehensive measure of negative $\operatorname{mood}(\mathrm{T} 1: M=$ 2.40, $S D=0.71, \alpha=.92 ; \mathrm{T} 3: M=2.18, S D=0.71, \alpha=.91)$.

\section{WRITING INTERVENTION}

In the experimental condition, participants were asked to write about self-defining memories for about 20 minutes once a week for 8 consecutive weeks. Selfdefining memories were introduced using instructions given in Singer and Moffitt (1991-1992, p. 242). To illustrate the concept of self-defining memories, participants were asked to imagine having just met a person they liked very much and going for a long walk together. Participants were encouraged to think of memories that would be able to convey how they have come to be the person they currently are. To further illustrate the concept, participants were told that self-defining memories usually share most of the following attributes (also taken from Singer \& Moffitt, 1991-1992): 
TABLE 4: Descriptive Statistics and Two-Tailed Correlations Among Variables (Study 3, $n=70$ )

\begin{tabular}{|c|c|c|c|c|c|c|c|}
\hline & 1 & 2 & 3 & 4 & 5 & M & SD \\
\hline 1 Fear of rejection & $(.76)$ & $.40 * * * *$ & $.41 * * * *$ & $.22 *$ & $.21 *$ & 5.32 & 2.73 \\
\hline 2 Fear of failure & & $(.77)$ & $.32 * * * *$ & .17 & .11 & 3.96 & 2.31 \\
\hline 3 Neuroticism & & & $(.78)$ & $.44 * * * *$ & $.37 * * * *$ & 2.79 & 0.66 \\
\hline 4 Negative mood, $T$ & & & & $(.92)$ & $.48 * * * *$ & 2.40 & 0.71 \\
\hline 5 Negative mood, $T$ & & & & & $(.91)$ & 2.18 & 0.71 \\
\hline
\end{tabular}

NOTE: Figures in parentheses are reliabilities estimated by coefficient alpha.

$* p<.10 . * * * * p<.01$.

TABLE 5: Hierarchical Regression of Negative Mood at Time 3 (Study 3)

\begin{tabular}{|c|c|c|c|c|c|}
\hline Step & Variable & $\Delta \mathrm{R}^{2}$ & df & $\Delta \mathrm{F}$ & $\beta^{\mathrm{a}}$ \\
\hline \multirow[t]{3}{*}{1} & Control variables & .260 & 2,67 & $11.78 * * * *$ & \\
\hline & Negative mood, Time 1 & & & & $.39 * * *$ \\
\hline & Neuroticism & & & & $.20 * *$ \\
\hline \multirow[t]{3}{*}{2} & Main effects & .013 & 2,65 & .60 & \\
\hline & Fear of rejection (FR) & & & & .05 \\
\hline & Experimental condition & & & & -.11 \\
\hline 3 & FR $\times$ Experimental Condition & .072 & 1,64 & $7.09 *$ & $-.48 * * *$ \\
\hline \multicolumn{2}{|c|}{ Cumulative $R^{2}$} & .346 & 5,64 & $6.78 * * * *$ & \\
\hline
\end{tabular}

a. $\beta$ is the standardized regression coefficient in the regression equation.

$* * p=.055 . * * * p<.05 . * * * * p<.01$.

(a) The memory is at least 1 year old.

(b) It is a memory from your life that you remember clearly and that still feels important to you even when you think about it today.

(c) It may be a memory that is positive or negative, or both, in how it makes you feel. The only important aspect is that it leads to strong feelings.

Participants were asked to write about self-defining memories related to four general topics. The topics selected for this study-spare time, school, friends, and family-were chosen because we wanted to make sure participants were writing about memories that represented their precollege life. Over the course of the study, each participant wrote two essays on each of the four topics. The order of topics (see above) was the same for all the participants. After writing a self-defining memory, participants were asked to rate the intensity of positive affect and negative affect aroused by the memory on a 7point scale with endpoints labeled weak (1) and strong (7). Ratings of positive and negative affect were averaged across the eight essays. At the beginning of the writing period, participants were asked to select a day and a specific time on which they were to write their self-defining memories (most participants picked Sunday afternoon). An inspection of the booklets and further questioning of participants revealed that all participants adhered to these instructions. On average, the self-defining memories reported in this study were rated as arousing both positive affect $(M=4.75 ; S D=1.06)$ and negative affect
$(M=3.25 ; S D=0.89)$ of medium intensity. Because positive and negative affects were highly correlated $(r=-.83$, $p<.001)$, ratings of negative affect were reversed and combined with positive affect to yield an index of resultant valence of self-reported memories $(M=4.75, S D=$ $.93)$.

Results

\section{DESCRIPTIVE STATISTICS AND PRELIMINARY ANALYSES}

As can be seen in Table 4, fear of rejection was significantly associated with neuroticism and fear of failure. Neuroticism also correlated significantly with negative mood at both T1 and T3. Exploratory analyses showed that neither gender nor age had significant impact on the results reported below.

\section{NEGATIVE MOOD AT THE END OF THE SEMESTER}

Negative mood at T3 was analyzed by employing a hierarchical regression analysis that (as in Study 2) controlled for the effects of initial negative mood and neuroticism. Thus, negative mood at $\mathrm{T} 1$ and neuroticism were entered in the first step of the hierarchical regression, followed by fear of rejection and the experimental condition (Step 2), and the multiplicative interaction of fear of rejection and the experimental condition (Step 3). After controlling for initial negative mood and neuroticism, the interaction of fear of rejection and the experimental condition predicted negative $\operatorname{mood}$ at T3, $\beta=-.42, S E_{\beta}=.16, \Delta R^{2}=.072, t(64)=2.66, p=$ 


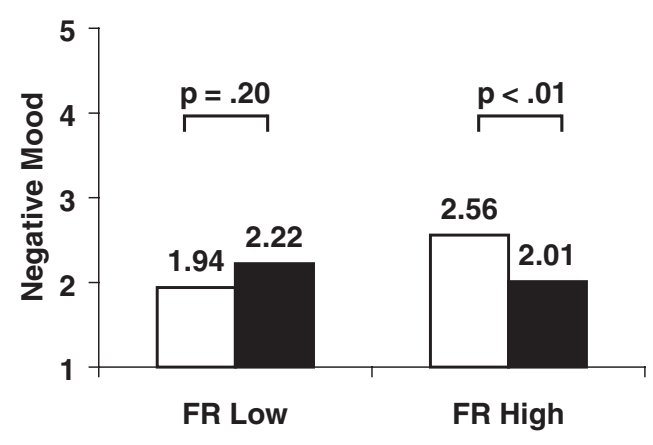

\section{$\square$ Control Self-Defining Memories}

Figure 2 Negative mood at Time 3 as a function of the experimental condition and fear of rejection (Study 3 ).

NOTE: $F R=$ fear of rejection.

.01 (see also Table 5). Figure 2, which was prepared according to the procedure outlined in Study 2, suggests that individuals high in fear of rejection who wrote about self-defining memories reported lower negative mood at the end of the semester than individuals high in fear of rejection in the nonwriting control condition. Supplementary post hoc analysis employing the JohnsonNeyman technique showed that the difference between the two conditions was not significant for individuals low in fear of rejection, $t(64)=1.29, p=.20$, two-tailed test. In contrast, the difference between the two conditions was significant for individuals high in fear of rejection, $t(64)=$ 2.68, $p<.01$, two-tailed test.

Additional analyses were carried out to test whether fear of rejection was related to the resultant valence of the self-defining memories and whether resultant valence predicted changes in negative mood. Fear of rejection turned out to be unrelated to resultant valence $(r=.19, p>.20)$. Also, after controlling for negative mood at $\mathrm{T} 1$ and neuroticism, resultant valence did not predict negative $\operatorname{mood}$ at T3, $\beta=-.14, S E_{\beta}=.11, t(32)=$ $1.29, p>.20$. Also, there was no indication that the pattern of resultant valence over time was related to changes in negative mood. These findings suggest that the effects of writing about self-defining memories did not depend on the valence of the memories participants wrote about.

As in Study 2, we also tested whether neuroticism and fear of failure moderated the effects of the writing condition. A hierarchical regression of negative mood at T3 on initial negative mood (Step 1), neuroticism and the experimental condition (Step 2), and the multiplicative interaction of predictors (Step 3) yielded significant effects for initial negative mood and neuroticism. However, the interaction of neuroticism and the experimental condition did not reach significance, $\beta=-.23, S E_{\beta}=$
$.16, t(65)=1.48, p=.14$. Similarly, the interaction of fear of failure and the experimental condition did not significantly predict negative mood at T3 (controlling for negative $\operatorname{mood}$ at $\mathrm{T} 1$ and neuroticism, $\beta=-.19, S E_{\beta}=.15$, $t(65)=1.27, p>.20$.

\section{Brief Discussion}

The results of Study 3 showed that the long-term emotional effects of writing about self-defining memories depend on an individual's fear of rejection. Individuals high in fear of rejection seemed to benefit from writing about self-defining memories, reporting levels of negative mood at the end of the semester as low as the levels of individuals low in fear of rejection. Individuals high in fear of rejection who did not write about self-defining memories reported increased negative mood at the end of the semester. In contrast, writing about self-defining memories did not seem to have a beneficial effect for individuals low in fear of rejection. As in Study 2, there was no evidence that neuroticism or fear of failure moderated the consequences of the writing intervention.

Additional analyses suggested that the effects of the writing intervention did not depend on the valence of self-defining memories. On average, the self-defining memories reported by our participants were both positive and negative, which resonates with the finding that individuals who benefit from emotional expression tend to use both positive and negative emotion words in their writing (e.g., Pennebaker \& Francis, 1996). Also, King and Miner (2000) found that writing about the positive aspects of highly upsetting experiences is associated with better physical health in the following 5 months. Thus, it does not seem necessary to focus exclusively on negative aspects of emotional experiences for positive effects of emotional expression to occur.

Having participants write about self-defining memories (rather than stressful experiences) reduced attrition rate. Most probably, individuals were less concerned about writing about self-defining memories and may have felt no need to drop out of the study. The effects of the writing intervention were comparable for Studies 2 and 3, suggesting that writing about self-defining memories and stressful experiences seemed to have comparable effects. We suggest that stretching out the writing intervention in Study 3 may have helped to increase the effect of writing about self-defining memories (cf. Smyth, 1998).

\section{GENERAL DISCUSSION}

The results of Studies 2 and 3 consistently demonstrate that individuals high in fear of rejection who wrote about emotional experiences reported lower levels of negative mood 5 to 6 weeks after the writing intervention than did individuals high in fear of rejection who did not 
write about emotional topics. In contrast, the writing interventions of Studies 2 and 3 did not have a significant impact on negative mood for individuals low in fear of rejection. It is noteworthy that this research obtained converging results using two different writing interventions (writing about highly stressful experiences and about self-defining memories). This methodological convergence instills confidence in the robustness of our findings. Our data also allowed for testing whether other variables than fear of rejection moderate the consequences of written emotional expression. Neuroticism and fear of failure could not be established as significant moderators of the relationship between emotional writing and negative mood in either of the studies. These results are in accordance with our hypothesis that fear of rejection is a unique moderator of the consequences of written emotional expression.

Our research was based on a set of related research findings: Perceptions of high levels of social support enable people to cope efficiently with stressful experiences, whereas low perceived social support is associated with reductions in positive mood and adaptive coping strategies (e.g., Pierce \& Lydon, 1998). Study 1 demonstrated that individuals high in fear of rejection report more interpersonal hassles and may thus experience a lack of perceived social support. Low social support, in turn, may increase their vulnerability to stressful events. Studies 2 and 3 suggest that written emotional expression can compensate for an impairment of the capacity to down-regulate negative mood caused by diminished perceptions of social support that are associated with fear of rejection. In accord with Pennebaker's conception, further results of Study 2 suggested that individuals high in fear of rejection benefit from emotional expression by developing a new understanding of upsetting experiences. Finding meaning in upsetting experiences can help people to integrate traumatic experiences, but it may also promote self-regulatory processes (King \& Miner, 2000). Study 3 found that the emotional valence of the essays written in the experimental condition did not predict long-term reductions in negative mood, suggesting that it is not necessary to focus on extremely negative events for the beneficial effects of emotional expression to occur (cf. King \& Miner, 2000).

In sum, these findings suggest that individuals high in fear of rejection benefit from written emotional expression by gaining a new understanding of emotional experiences, thereby promoting general self-regulatory processes (Greenberg, Wortman, \& Stone, 1996; King \& Miner, 2000). In our view, written emotional expression is an intentional strategy that may serve to compensate for a lack of perceived social support typically experienced by individuals high in fear of rejection. Although our data are generally consistent with this assumption, we do acknowledge the need for further studies to investigate the relationship between emotional expression and perceived social support. For example, it may be possible that emotional expression can enhance perceptions of social support among individuals high in fear of rejection, which may add to its effectiveness. Future studies should address this issue.

Although most research has focused on the effects of emotional expression on physical health, Smyth's (1998) meta-analysis also reported a significant effect of emotional expression on psychological well-being. It is important to note that we did not find main effects of the writing intervention in both studies, which stands in contrast to the meta-analysis by Smyth (1998). However, the indexes of psychological well-being analyzed by Smyth included such diverse measures as intrusions, general temperament, and adjustment to college, along with measures of negative affect. Thus, it may not be feasible to directly compare the effects of Studies 2 and 3 with the overall effect size for psychological well-being reported by Smyth (1998). However, the simple effect sizes of the writing intervention in Studies 2 and 3, though not significant, were in the expected direction (Study 2: $d=.12$; Study 3: $d=.24$ ), and at least the effect size of Study 3 falls within the range of effect sizes for measures of psychological well-being reported in Smyth's meta-analysis. Together, these data suggest that the effects of emotional expression may be straightforward for health benefits and may depend more heavily on moderators such as fear of rejection for long-term mood changes.

Our results clearly suggest that writing about stressful experiences or self-defining memories does not seem to ameliorate negative mood in individuals low in fear of rejection. Quite in contrast, both studies suggested (although these effects were not statistically significant) that written emotional expression may lead to an increase in negative mood in individuals low in fear of rejection. These results correspond with research suggesting that intentional confrontation with stressful experiences may not be generally beneficial. For example, Wortman and Silver $(1989,2001)$ maintained that "working through" the emotions associated with a loss is, for most people, neither a necessary nor a sufficient condition for successful coping. In contrast, there is evidence that a deliberate confrontation with a traumatic event can even prolong negative emotions. In their first review, Wortman and Silver (1989, p. 352) cited data that suggested that active attempts to make sense of a loss are linked to higher reported distress 18 months after the event. More recently, McNally, Bryant, and Ehlers (2003) argued that psychological debriefing following a stressful or traumatic experience-which typically involves disclosing one's thoughts and feelings about a traumatic or stressful event, often in a group of fellow survivors- 
though often rated as helpful has failed to prove its effectiveness in controlled studies and that some studies even suggest that debriefing may impede natural recovery from traumatic events (McNally et al., 2003, pp. 61-64). It seems that people possess a natural ability to cope with stressful and even traumatic events, and that this natural capacity is not dependent on, or can even be impeded by, intentional efforts to disclose or make sense of the experience. We suspect that the natural capacity to adapt to stressful experiences is largely intact in individuals low in fear of rejection and that they therefore simply do not have to rely on written emotional expression as a means of down-regulating negative mood. On the other hand, the natural capacity to cope with stressful events may be impaired in individuals high in fear of rejection (probably due to low levels of perceived social support), which may render an intentional coping strategy such as written emotional expression more effective.

In sum, our research yielded encouraging results that showed that measures of individual differences can be successfully applied in research on coping with stressful experiences through written emotional expression. By extending the scope and using different methodologies in future research, we may better be able to help people find more adaptive ways of coping with stress.

\section{NOTES}

1. Following suggestions by P. Cohen et al. (2003), continuous variables were centered before subjecting them to hierarchical regression analyses.

2. An additional intent-to-treat analysis was performed in which missing values for participants who quit participation were imputed by negative mood at T1 (the last observation carried forward). After controlling for initial negative mood and neuroticism, this analysis yielded a significant interaction of fear of rejection and the experimental condition, $\beta=.35, S E_{\beta}=.12, \Delta R^{2}=.057, t(77)=2.81, p<.01$. The pattern of this interaction was similar to the one illustrated in Figure 1.

3 . The booklet contained other questionnaires that are not relevant to the present investigation. The vast majority of participants filled in the questionnaires that were handed out at $\mathrm{T} 1$ in less than 60 minutes.

\section{REFERENCES}

Aiken, L. S., \& West, S. G. (1991). Multiple regression: Testing and interpreting interactions. Newbury Park, CA: Sage.

Bolger, N., Foster, M., Vinokur, A. D., \& Ng, R. (1996). Close relationships and adjustment to a life crisis: The case of breast cancer. Journal of Personality and Social Psychology, 70, 283-294.

Bolger, N., Zuckerman, A., \& Kessler, R. C. (2000). Invisible support and adjustment to stress. Journal of Personality and Social Psychology, 79, 953-961.

Borkenau, P., \& Ostendorf, F. (1993). NEO-Fünf-Faktoren Inventar (NEO-FFI) nach Costa und McCrae: Handanweisung [NEO-Five-Factor Inventory (NEO-FFI) according to Costa and McCrae: Manual]. Göttingen, Germany: Hogrefe.

Cohen, P., Cohen, J., West, S. G., \& Aiken, L. S. (2003). Applied multiple regression/correlation analysis for the behavioral sciences (3rd ed.). Hillsdale, NJ: Lawrence Erlbaum.

Cohen, S. (1992). Stress, social support, and disorder. In H. O. F. Veiel \& U. Baumann (Eds.), The meaning and measurement of social support (pp. 109-124). New York: Hemisphere.
Connor-Smith, J. K., \& Compas, B. E. (2002). Vulnerability to social stress: Coping as a mediator or moderator of sociotropy and symptoms of anxiety and depression. Cognitive Therapy and Research, 26, 39-55.

Costa, P., \& McCrae, R. (1987). Neuroticism, somatic complaints, and disease: Is the bark worse than the bite? Journal of Personality, 55 , 299-316.

Coyne, J. C., \& Downey, G. (1991). Social factors and psychopathology: Stress, social support, and coping processes. Annual Review of Psychology, 42, 401-425.

Eckenrode, J., \& Wethington, E. (1990). The process and outcome of mobilizing social support. In S. W. Duck \& R. C. Silver (Eds.), Personal relationships and social support (pp. 83-103). Thousand Oaks: Sage.

Elliot, A. J., \& Sheldon, K. M. (1998). Avoidance personal goals and the personality-illness relationship. Journal of Personality and Social Psychology, 75, 1282-1299.

Emmons, R., \& King, L. (1988). Conflict among personal strivings: Immediate and long-term implications for psychological and physical well-being. Journal of Personality and Social Psychology, 54, 1040-1048.

Francis, M. E., \& Pennebaker, J. W. (1992). Putting stress into words: The impact of writing on physiological, absentee, and selfreported emotional well-being measures. American Journal of Health Promotion, 6, 280-287.

Gable, S. L., Reis, H. T., \& Elliot, A. J. (2003). Evidence for bivariate systems: An empirical test of appetition and aversion across domains. Journal of Research in Personality, 37, 349-372.

Georges, E. (1995). A cultural and historical perspective on confession. In J. W. Pennebaker (Ed.), Emotion, disclosure, and health (pp. 11-22). Washington, DC: American Psychological Association.

Greenberg, M. A., Wortman, G. B., \& Stone, A. A. (1996). Emotional expression and physical health: Revising traumatic memories or fostering self-regulation. Journal of Personality and Social Psychology, $71,588-602$.

Holahan, C. J., Moos, R. H., Holahan, C. K., \& Brennan, P. L. (1997). Social context, coping strategies, and depressive symptoms: An expanded model with cardiac patients. Journal of Personality and Social Psychology, 72, 918-928.

Kehr, H. M. (2004). Implicit/explicit motive discrepancies and volitional depletion among managers. Personality and Social Psychology Bulletin, 30, 315-327.

King, L. A., \& Miner, K. N. (2000). Writing about the perceived benefits of traumatic experiences: Implications for physical health. Personality and Social Psychology Bulletin, 26, 220-230.

Klein, K., \& Boals, A. (2001). Expressive writing can increase working memory capacity. Journal of Experimental Psychology: General, 130, 520-533.

Langens, T. A., \& Schmalt, H.-D. (2002). Emotional consequences of positive daydreaming: The moderating role of fear of failure. Personality and Social Psychology Bulletin, 12, 1725-1735.

Langens, T. A., \& Stucke, T. S. (in press). Stress and mood: The moderating role of activity inhibition. Journal of Personality.

McNair, D. M., Lorr, M., \& Droppleman, L. F. (1971). Profile of mood states. San Diego, CA: Educational \& Industrial Testing Service.

McNally, R. J., Bryant, R. A., \& Ehlers, A. (2003). Does early psychological intervention promote recovery from posttraumatic stress? Psychological Science in the Public Interest, 4, 45-79.

Mehrabian, A., \& Ksionzky, S. (1974). A theory of affiliation. Toronto, Canada: Lexington Books.

Park, C. L., \& Blumberg, C. J. (2002). Disclosing trauma through writing: Testing the meaning-making hypothesis. Cognitive Therapy and Research, 26, 597-616.

Parkinson, B., \& Totterdell, P. (1999). Classifying affect-regulation strategies. Cognition and Emotion, 13, 277-303.

Pennebaker, J. W., \& Beall, S. K. (1986). Confronting a traumatic event: Toward an understanding of inhibition and disease. Journal of Abnormal Psychology, 95, 274-281.

Pennebaker, J. W., \& Francis, M. E. (1996). Cognitive, emotional, and language processes in disclosure. Cognition and Emotion, 10, 601626. 
Pennebaker, J. W., Mayne, T., \& Francis, M. (1997). Linguistic predictors of adaptive bereavement. Journal of Personality and Social Psychology, 72, 863-871.

Pennebaker, J. W., \& Seagal, J. D. (1999). Forming a story: The health benefits of narrative. Journal of Clinical Psychology, 55, 1243-1254.

Pierce, T., \& Lydon, J. (1998). Priming relational schemas: Effects of contextually activated and chronically accessible interpersonal expectations on responses to a stressful event. Journal of Personality and Social Psychology, 75, 1441-1448.

Richards, J. M., Beal, W. E., Seagal, J. D., \& Pennebaker, J. W. (2000). Effects of disclosure of traumatic events on illness behavior among psychiatric prison inmates. Journal of Abnormal Psychology, 109, 156-160.

Rosenblatt, P. C., Meyer, C. J., \& Karis, T. A. (1991-1992). Internal interactions with God. Imagination, Cognition and Personality, 11, 85-98.

Shacham, S. (1983). A shortened version of the Profile of Mood States. Journal of Personality Assessment, 47, 305-306.

Singer, J. A., \& Moffitt, K. H. (1991-1992). An experimental investigation of specificity and generality in memory narratives. Imagination, Cognition, and Personality, 11, 233-257.

Singer, J. A., \& Salovey, P. (1993). The remembered self: Emotions and memory in personality. New York: Free Press.

Smyth, J. M. (1998). Written emotional expression: Effect sizes, outcome types, and moderating variables. Journal of Consulting and Clinical Psychology, 66, 174-184.

Sokolowski, K., \& Schmalt, H.-D. (1996). Emotionale und motivationale Einflußfaktoren in einer anschlußthematischen Konfliktsituation [Effects of emotion and motivation in an affiliation conflict]. Zeitschrift für Experimentelle Psychologie, 3, 461-482.

Sokolowski, K., Schmalt, H.-D., Langens, T. A., \& Puca, R. M. (2000). Assessing achievement, affiliation, and power motives all at once-the Multi-Motive Grid (MMG). Journal of Personality Assessment, 74, 126-145.
Spera, S. P., Buhrfeind, E. D., \& Pennebaker, J. W. (1994). Expressive writing and coping with job loss. Academy of Management Journal, 37, 722-733

Streiner, D. L. (2003). Being inconsistent about consistency: When coefficient alpha does and doesn't matter. Journal of Personality Assessment, 80, 217-222.

Stroebe, W., \& Stroebe, M. (1996). The social psychology of social support. In E. T. Higgins \& A. M. Kruglanski (Eds.), Social psychology: Handbook of basic principles (pp. 597-621). New York: Guilford.

Suh, E., Diener, E., \& Fujita, F. (1996). Events and subjective wellbeing: Only recent events matter. Journal of Personality and Social Psychology, 70, 1091-1102.

Vinokur, A. D., \& Van Ryan, M. (1993). Social support and undermining in close relationships: Their independent effects on the mental health of unemployed persons. Journal of Personality and Social Psychology, 65, 350-359.

Vorauer, J. D., Cameron, J. J., Holmes, J. G., \& Pearce, D. G. (2003). Invisible overtures: Fears of rejection and the signal amplification bias. Journal of Personality and Social Psychology, 84, 793-812.

Wellenkamp, J. (1995). Cultural similarities and differences regarding emotional disclosure: Some examples from Indonesia and the Pacific. In J. W. Pennebaker (Ed.), Emotion, disclosure, and health (pp. 293-311). Washington, DC: American Psychological Association.

Wortman, C. B., \& Silver, R. C. (1989). The myths of coping with loss. Journal of Consulting and Clinical Psychology, 57, 349-357.

Wortman, C. B., \& Silver, R. C. (2001). The myths of coping with loss revisited. In M. S. Stroebe \& R. O. Hansson (Eds.), Handbook of bereavement research: Consequences, coping, and care (pp. 405-429). Washington, DC: American Psychological Association.

Received March 4, 2004

Revision accepted September 28, 2004830 